ノート・ Note

\title{
A Speculation on an Absorption Center Induced in the Photochromic Glass Containing Silver Halide Crystals
}

\author{
By \\ Yoshiro MORIYA \\ (Government Industrial Research Institute, Osaka)
}

\begin{abstract}
ハロゲン化銀結晶を含むフォトクロミックガラス中に
誘起される吸収センターに関する一推論
\end{abstract}

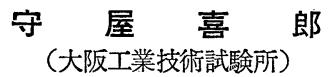

In the photochromic glass containing silver halide crystals, at least three absorption bands (band I, II and III are induced by the irradiation with UVrays. Their peaks are located at about $360 \mathrm{~nm}$, about $500 \mathrm{~nm}$ and above $650 \mathrm{~nm}$, respectively, as shown in Fig. 1.

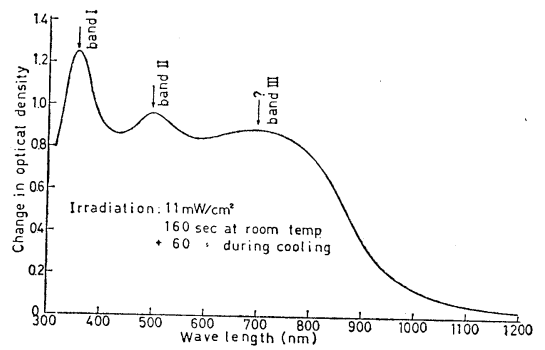

Fig. 1. UV-induced absorption spectrum of a photochromic glass containing $\mathrm{AgCl}$ crystals measured at liquid nitrogen temperature. Irradiation: High pressure $\mathrm{Hg}$ light through UV-D25 filter.

It has been already proposed by the author that band II is attributed to small spherical silver particles formed in silver halide crystals and band I may be related to $\mathrm{X}_{2}^{-}$(dihalogen ion or $V_{\mathrm{k}}$ center) rather than silver particles ${ }^{1}$. However, the assignment has remained unsolved on band III. This note concerns with the speculation on the center responsible for band III. Band III has apparently the following features ${ }^{1)}$. (1) Band III becomes more pronounced and its apparent peak shifts to longer wavelengths with increasing amount of the irradiated UV-rays, or with increa- sing extent of the darkening, and also with increasing size of silver halide crystals. (2) Band III is observed at longer wavelengths in the glass containing $\mathrm{AgCl}$ ${ }_{1-x} \mathrm{Br}_{x}$ crystals with higher proportion of $x$.

The position of band III is apt to be affected by the addition of the minor components. For example, it shifts greatly to shorter wavelengths with increasing amount of CdO. (4) Band III appears to shift to shorter wavelengths with fading. Among these features, (1), (2) and (4) are common to those of band II. Nevertheless, it is difficult to attribute band III to the same center as that for band II, because the peak of band III is located at far longer wavelength than that expected for small spherical silver particles in silver halide crystals. Therefore, the possibility of the non-spherical silver particles as the center for band III was examined.

According to $\mathrm{Mie}^{2)}$, the absorption coefficient, $K$, per unit volume concentration of infinitesimally small spherical particles in the solution is expressed by Eq. (1).

$$
K=\left(6 \pi / \lambda^{\prime}\right) \operatorname{Im}\left(-a_{1}\right)
$$

where $\lambda^{\prime}=\lambda / m_{0}\left(\lambda\right.$; wavelength, $m_{0}$; refractive index of surrounding medium) and $a_{1}=m^{\prime 2}-1 / m^{\prime 2}+2\left(m^{\prime}\right.$ $=m / m_{0}, m$; complex refractive index of the particle). Im signifies that only the imaginary part of $a_{1}$ is taken.

Gans extended the Mie theory and derived the equation for the case including both infinitesimally small prolate and oblate ellipsoids of revolution ${ }^{32}$. According to him, $a_{1}$ in Eq. (1) is $a_{1}=a_{1}{ }^{\prime} / 3+2 a_{1}{ }^{\prime \prime} / 3$ where $a_{1}{ }^{\prime}=\frac{m^{\prime 2}-1}{3+\left(3 P^{\prime} / 4 \pi\right)\left(m^{\prime 2}-1\right)}$ 
and $a_{1}{ }^{\prime \prime}=\frac{m^{\prime 2}-1}{3+\left(3 P^{\prime \prime} / 4 \pi\right)\left(m^{\prime 2}-1\right)}$ with $P^{\prime}+2 P^{\prime \prime}$ $=4 \pi$. For prolate ellipsoids

$$
P^{\prime}=4 \pi \frac{1-e^{2}}{e^{2}}\left(\frac{1}{2 e} \ln \frac{1+e}{1-e}-1\right) \text { and for oblate }
$$
ellipsoids $P^{\prime}=\frac{4 \pi}{e^{2}}\left(1-\frac{\sqrt{1-e^{2}}}{e} \arcsin e\right)$ where $e=\left(A^{2}-B^{2}\right)^{1 / 2} / A$ with axial ratio $B / A$.

Using these equations, Skillman et al. computed the absorption curves due to eleven shapes of prolate silver ellipsoids in gelatin and confirmed that the computed peak position agreed fairly well with the experimentally observed one $e^{4)}$.

In present study, the absorption coefficient, $K$, ranging from 380 to $800 \mathrm{~nm}$, was similarly computed by using Tosbac 3400 for two kinds of silver ellipsoids surrounded by the medium with refractive index equal to that of $\mathrm{AgCl}$ crystal. As optical constants, those calculated by applying the leastsquare method to the values for silver metal given

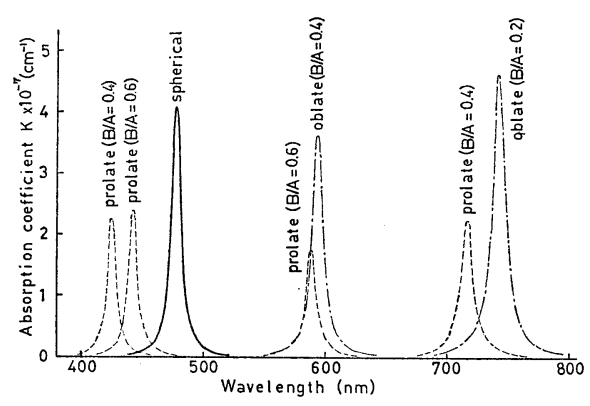

Fig. 2. Computed absorption curves for prolate and oblate ellipsoids of several different axial ratios, together with for spherical particles.

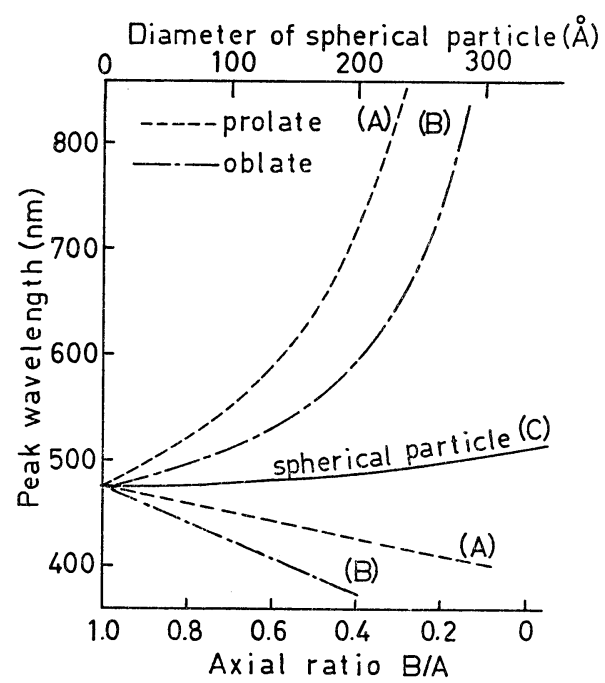

Fig. 3. Changes in peak position of absorption due to silver particles in $\mathrm{AgCl}$ crystals with (A) and (B) axial ratio of prolate and oblate ellipsoids and (C) diameter of spherical particle. by Johnson et $\mathrm{al}^{5)}$. and Otter ${ }^{6)}$ in order to cover the wide range of wavelength were adopted for the computation. In Fig. 2 are shown the computed absorption curves for prolate and oblate ellipsoids of several different axial ratios and in Fig. 3 are shown. the changes in the peak position of absorption curve with the axial ratio of ellipsoids. In the latter figure is also shown the change in peak position with the diameter of spherical particle, computed using more complicated $\mathrm{Mie}^{\prime} \mathrm{s}$ equation than $\mathrm{Eq}$. $(1)^{2)}$. We can understand from these figures that the small departure from spherical shape affects the peak position much more than the change in particle diameter and also that about $720 \mathrm{~nm}$ at which. band III is centered corresponds to the peak position for prolate silver ellipsoids with $B / A \sim 0.4$ or oblate silver ellipsoids with $B / A \sim 0.22$. Consequently, as. far as these results are concerned, band III can be attributed to such silver ellipsoids.

While, according to the calculation by Jones et al. ${ }^{7)}$, the close aggregation of small silver spheres shifts the absorption peak to longer wavelengths, being from $425 \mathrm{~nm}$ for isolated spheres to $525 \mathrm{~nm}$ for the aggregates in linear contact of four spheres of sphered iameter of $400 \AA$. This suggests that band III may be due to the needle-like aggregates of too small spherical silver particles. Thus real situation is not so simple. However, if band III can be attributed to the non-spherical small silver particles formed in silver halide crystals, whether they are ellipsoids or aggregates of spherical particles, the similarity of the features of band III to those of band II is understandable. The shift of absorption peak to shorter wavelengths with addition of $\mathrm{CdO}$ and with fading is probably ascribed to the change of the shape of silver particles to more spherical form. The difference between the computed band width and experimentally observed one should be explained. by the non-uniformity of particle shape and size, and the so-called surface plasma resonance effect ${ }^{8}$, etc.

\section{References}

1) Y. Moriya, Tenth ICG (1974), Kyoto, No. 5, 5360, ibid. Yogyo-Kyokai-Shi, 83 [2] 75-80 (1975)*.

2) G. Mie, Ann. Phys. 25, 377-445 (1908).

3) R. Gans, Ann. Phys. 37, 881-900 (1912), ibid. 47 270-84 (1915).

4) D.C. Skillman and C.R. Berry, J. Chem. Phys. 48. 3297-04 (1968).

5) P.B. Johnson and R.W. Christy, Phys. Rev. B, 6.

* The numerical values in the latter paper should be corrected as follows.

$\begin{array}{cccc}\text { page } & \text { line } & \text { error } & \text { right } \\ 79 & 21 & 7.08 \times 10^{-12} & 7.1 \times 10^{-12} \\ \text { " } & 22 & 9.8 \times 10^{-15} & 9.7 \times 10^{-15} \\ \text { " } & 24 & 2.66 \times 10^{-5} & 2.7 \times 10^{-5} \\ \text { " } & \text { " } & 9.85 \times 10^{-6} & 9.8 \times 10^{-7}\end{array}$


4370-79 (1972).

6) W. Otter, Z. Phys. 161 163-78 (1961).

7) R.C. Jones and G.R. Bird, Photo. Sci. and Eng. 16, 16-24 (1972).
8) A. Kawabata and R. Kubo, J. Phys. Soc. Japan 21, 1765-72 (1966).

[Received October 27,1975]

\title{
研究速報・Short Communication
}

\section{Reaction between $\mathrm{Al}_{2} \mathrm{O}_{3}$ and Silicon in Nitrogen Atmosphere}

\author{
By \\ Yoshizo INOMATA, Ken YUKINO and Toshiaki WADA \\ (National Institute for Researches in Inorganic Materials)
}

\author{
窒素雾囲気中における $\mathrm{Al}_{2} \mathrm{O}_{3}$ とシリコンとの反応 \\ 猪股吉三・雪野 健・和田符璋
}

Mixed powder of $\mathrm{Al}_{2} \mathrm{O}_{3}$ (particle size : ca. $0.1 \%$, purity in ig. loss free state $>99.9 \%$, ig. loss $: 0.5$ $\%$ ) and silicon (particle size : ca. $10 \mu$, purity $>$ $99.9 \%$ ) in equal weight was pressed in $1 \mathrm{~g}$ disk $(15 \phi \times 4 \mathrm{~mm})$ and reacted at $1410^{\circ} \mathrm{C}$ for $10 \mathrm{~h}$ in nitrogen atmosphere of 1 atm. The reaction product was consisted of $\beta-\mathrm{Si}_{3} \mathrm{~N}_{4}, \alpha-\mathrm{Al}_{2} \mathrm{O}_{3}, \quad \mathrm{AlN}$ and $\alpha-\mathrm{Si}_{3}$ $\mathrm{N}_{4}$. Free silicon was not detected in the reaction product, but weight increment observed after the reaction was lower than the theoretical value, 34\% expected from simple nitridation of silicon.

By annealing the sample at 1730 and $1780^{\circ} \mathrm{C}$ in $\mathrm{Si}_{3} \mathrm{~N}_{4}$ crucible by r.f. heating with molybdenum susceptor under nitrogen atmosphere of $1 \mathrm{~atm}$, results as shown in Table 1 were obtained. Those data clearly show following phase change being occurred during the initial reaction at $1410^{\circ} \mathrm{C}$ and the annealing stage at $1730 \sim 1780^{\circ} \mathrm{C}$.

$$
\begin{aligned}
& 3 \mathrm{Si}+\mathrm{Al}_{2} \mathrm{O}_{3}+\mathrm{N}_{2} \longrightarrow 2 \mathrm{AlN}+3 \mathrm{SiO} \uparrow \\
& \mathrm{Si}_{3} \mathrm{~N}_{4}+\mathrm{Al}_{2} \mathrm{O}_{3} \longrightarrow 2 \mathrm{AlN}+3 \mathrm{SiO} \uparrow+\mathrm{N}_{2} \uparrow \\
& \mathrm{Si}_{3} \mathrm{~N}_{4}-\mathrm{AlN}_{-}-\mathrm{Al}_{2} \mathrm{O}_{3} \text { solid solution } \\
& +\mathrm{AlN} \text { base solid solution }+\mathrm{SiO} \uparrow+\mathrm{N}_{2} \uparrow
\end{aligned}
$$

Those reactions are quite similar to that between silicon and $\mathrm{SiO}_{2}{ }^{4)}$, and the decomposition of $\mathrm{Si}_{2} \mathrm{~N}_{2}$. $\mathrm{O}^{5)}$. The weight loss, $45.4 \%$ observed at $1780^{\circ} \mathrm{C}$ for $8 \mathrm{hr}$ heating, just coincides with the value calculated for oxygen free state according to first reaction. Similar consideration may be applied to the other systems of oxide-- $\mathrm{Si}_{3} \mathrm{~N}_{4}$ mixture or metalsilicon-oxynitride type compounds or solid solutions, especially in the process of pressureless sintering.

\section{References}

1) Y. Oyama, Yogyo-Kyokai-Shi 82 [7] 351-57 (1974).

2) L.J. Gauckler, H.L. Lukas and G. Petzow, J. Am. Ceram. Soc. 58 [7-8] 346-47 (1975).

3) K.H. Jack, "Sialons and Related Nitrogen Ceramics" Preprints in series symposium (Nov., 1975 in Tokyo) p. 1-51.

4) H. Suzuki and T.Hosaka, Yogyo-Kyokai-Shi 75 [4] 111-19 (1967).

\begin{tabular}{|c|c|c|c|c|}
\hline $\begin{array}{l}\text { Temperature in } \\
\left({ }^{\circ} \mathrm{C}\right)\end{array}$ & $\begin{array}{l}\text { Time in } \\
\text { (h) }\end{array}$ & $\begin{array}{c}\text { Weight gain in } \\
(\%)\end{array}$ & Linear shrinkage in & Phases present \\
\hline 1410 & 10 & 19.2 & 0 & $\beta-\mathrm{Si}_{8} \mathrm{~N}_{4}>\alpha-\mathrm{Al}_{2} \mathrm{O}_{3}>\mathrm{AlN} \sim \alpha-\mathrm{Si}_{3} \mathrm{~N}_{4}$ \\
\hline 1730 & 2 & -12.5 & 2.6 & $\beta^{\prime}$-phase* $>$ AlN base polytype ${ }^{* *}$ \\
\hline 1730 & 4 & -28.7 & 3.1 & $\beta-\mathrm{Si}_{8} \mathrm{~N}_{4} \sim d-\mathrm{AlN}^{* *} \gg \mathrm{AlN}$ base polytype \\
\hline 1730 & 8 & -40.2 & 4.1 & AlN $>\beta-\mathrm{Si}_{8} \mathrm{~N}_{4} \gg$ AlN base polytype \\
\hline 1780 & 2 & -33.6 & 4.4 & $d$-AlN $\sim \beta-\mathrm{Si}_{3} \mathrm{~N}_{4}>$ AlN base polytype \\
\hline 1780 & 4 & -44.9 & 6.7 & $d$-AlN $>\beta-\mathrm{Si}_{8} \mathrm{~N}_{4}>$ AlN base polytype \\
\hline 1780 & 8 & -45.4 & 9.7 & $d$-AlN $>\beta-\mathrm{Si}_{8} \mathrm{~N}_{4} \gg$ AlN base polytype \\
\hline
\end{tabular}

5) Y. Inomata, ibid. 82 [10] 522-26 (1974).

[Received December 25,1975]

Table 1. Results observed after the reaction.

* $\beta^{\prime}$-phase is a solid solution having $\beta-\mathrm{Si}_{3} \mathrm{~N}_{4}$ type structure ${ }^{2)}$.

** Detailed description was given by K.H. Jack ${ }^{2)}, d$-AlN indicates faulty AlN. 